of us both, we found hardly any. We would both have been pleased to have known then of this collection of nine essays by Christine Overall.

The essays cover the following areas: reproductive rights in Canada; conflicts between mother and fetus, and mother and state; selective reduction of pregnancy; killing the fetus following termination of pregnancy; parental rights over frozen embryos; the coopting of feminist values by non-feminists working in the field; surrogate motherhood; access to IVF, and, keeping records, given the genetically and biologically complex relationships which reproductive technology facilitates. Each essay is short, clearly written and to the point. Although this volume will interest those researching in the area, individual chapters are presented in a way which will make them accessible and useful to students too.

One of the recurrent themes of the book is the way in which women are manipulated by the provision of reproductive technology but at the same time held to be entirely responsible for the decisions which they make as they try to cope with the personal implications. In this 'classic nowin situation' (page 51), women find that they are more blamed than admired for their decisions. Yet, the effects of such decisions upon women can be startling. Take this rather extreme example: '[O]ne woman's reproductive history includes three caesarean sections, a tubal ligation, a tuboplasty $\ldots$ after which she remained infertile, IVF with subsequent implantation of four embryos, selective termination of two of the fetuses, revelation via ultrasound that one of the remaining twins had "severe oligohydramnios ... and no evidence of a bladder or kidneys", spontaneous miscarriage of the abnormal twin, and intrauterine death of the remaining fetus' (page 49). Another theme is Overall's belief that women are not sufficiently informed about the possible effects of their decisions before they consent to procedures. Her recurrent example here is that the success rate of IVF is consistently over-estimated.

Her approach to each subject can be admired on three levels. First, she is unashamedly feminist in her consideration of the issues. Second, she exhibits a high degree of philosophical rigour. Third, her compassion and concern are always in evidence (though I possibly shouldn't separate this from her feminist approach since it flows just as much from her feminist ideals, as it is additional to them). One example of her caring ethos can be found in her treatment of access to IVF. After outlining the problems of both a rights and privilege approach to the question of who should have access to IVF, she critiques some feminist approaches, then goes on to give her own appraisal. Before doing so, though, she pauses to state that, whilst she hopes that in the face of truly informed consent, women will decline the offer of IVF, it is for each woman to decide for herself. She roundly rejects the proposition that IVF programmes should be halted by 'feminist maternalism that seeks to protect the best interests of the women affected by IVF' (page 150).

Perhaps the weakest contribution to the collection is the final essay, entitled 'Reproductive Engineering and Genealogy'. Although her overview of the difficulties of genealogy is complete and concise, Overall does not really make a case for keeping records in the first place. Although she gives arguments elsewhere supporting, for instance, the value of records for follow-up (which she regards as vital), the omission of such an argument in this essay is against the pattern of free-standing pieces elsewhere in the volume which makes it such a potentially valuable teaching tool.

The balance remains, however, firmly in favour of purchasing this book which, at $£ 10.95$, is certainly a cost-effective addition to personal collections as well as libraries.

HEATHER DRAPER Department of Biomedical Ethics University of Birmingham

\section{Articulations: the body and illness in poetry}

Edited by Jon Mukand, Iowa City, University of Iowa Press, 1994, 426 pages, $\$ 19.95$

In many matters, including medical matters, Britain tends to lag some years behind the USA. For example, the current interest in medical ethics was well established in the USA before it became established in the UK. Even now it is by no means universally taught in anything other than a superficial manner in many medical schools at the moment. It may well be that the recent General Medical Council (GMC) paper on undergraduate medical education will ensure a more intensive coverage of ethics. But just as this is happening in the UK there are some signs of a shift of emphasis in this aspect of medical education in the USA towards a broader 'medical $\vec{F}$ humanities' approach. There is a case $\stackrel{\vec{P}}{\rightarrow}$ for this. In this country and in the USA it has been the philosophers who have made the running. But philosophers tend to move towards abstractions which do not always appeal to practically-orientated medical students and doctors. For such students the particularities of literature can sometimes be a humanising influence when philosophy cannot. Hence, in the USA there have grown up departments of the 'medical humanities' which may contain philosophers or 'ethicists' but will also contain historians or teachers of literature. Jon Mukand's anthology is one which could be used in a course on the 'medical humanities'.

John Mukand is a physician and poet who has already published, in 1987, Sutured Words, a volume of poems to help patients, their families and friends to come to terms with the complexities of healing, illness and death. In the present volume Mukand has addeg of more than a hundred new poems, an he provides a few pages of introduction to the anthology. The poems are main by contemporary American poets and are divided into sections with titles such as 'The body: just where grace resides'; 'The medical environment: the hospital smell combs my nostrils', and 'Patients' views of illness: the darkness within me is growing'. There is a section with poems by care-givers, and sections with poems on most areas of medical concern. Just as not every student or doctor cares for philosophical argument, so not all will appreciate the complexity and intensity of contemporary poetry. But for those who do this is a worthwhile anthology and contribution to the 'medical humanities'.

R S DOWNIE Professor of Philosophy, 응 University of Glasgow

\section{Medical law: text with materials}

I M Kennedy and A Grubb, London, Butterworths, 1994, 1,423 pages, $£ 30.95$ (sc)

This is the second edition of Medical law: Text with Materials. As the name suggests the book provides statutes, cases and articles along with extensive commentary. The text draws upon 